Revista Iberoamericana, Vol. LXXV, Núm. 228, Julio-Septiembre 2009, 841-864

\title{
LA POETIZACIÓN DEL ATLÁNTICO Y EL DILEMA DEL COMPROMISO: JOSÉ SARAMAGO, FERNANDO PESSOA, PABLO NERUDA
}

\author{
POR \\ LuÍs MADUREIRA \\ University of Wisconsin, Madison
}

\begin{abstract}
Soñaba con una isla que no se vislumbraba en el presente, donde él también estaba, sino que por decreto divino reposaba en la irrealidad, o el no-ser, del día anterior [...] inasequible como si hubiera huido hacia el pasado.

Umberto Eco, La isla del día de antes

Sou uma figura de romance por escrever.

Bernardo Soares

(semi-heterónimo de Fernando Pessoa)
\end{abstract}

“O começo étudo”, comenta lacónicamente uno de los narradores de Guimarães Rosa en Sagarana, refiriéndose a la estructura del relato en una estória que empieza tres veces (152). Como observa Edward Said en Beginnings, todo inicio no es sino una ficción necesaria, una concesión de nuestras mentes irrevocablemente finitas a un absoluto inalcanzable (77). Quizás porque el aspecto que otorga a los comienzos su identidad tiene como único objetivo su propia y constante clarificación (Said 73), hay principios que se apoderan de nosotros, que invaden la mente y regresan a la memoria con la agridulce insistencia de un diente suelto o del fragmento trillado de un estribillo que siempre aborrecimos. Desde que di por primera vez con ella hace más de dos décadas en una soleada tarde de California, la frase inaugural de $O$ ano da morte de Ricardo Reis [El año de la muerte de Ricardo Reis] se ha rehusado a abandonarme. Ésta fue la primera novela de Saramago que leí, y a mí, como al mismo escritor, "me sigue gustando mucho, muchísimo" (Halperín 70). Se trata de "aqui o mar acaba e a terra principia”, palabras que se repiten en mi recuerdo como una inscripción labrada en un cipo erigido a la orilla del mar. Precisamente allí, en ese borde del Atlántico donde el litoral portugués parece desplegarse angustiadamente mar adentro antes de emprender su abrupta ascensión rumbo al norte -en el lugar que las guías turísticas y los letreros de la ruta de Sintra proclaman "el punto más 
occidental de Europa”-, fue exactamente allí, en el Cabo da Roca, donde encontré pocos años después el reflejo quiásmico de esa misma frase grabada sobre una placa colocada en 1979 por el ayuntamiento de Sintra a fin de fijar con un lance característicamente épico ese término geográfico: “Aqui [...] onde a terra se acaba e o mar começa”. Se trata pues de un verso de Os Lusíadas de Luís de Camões, cuando Vasco da Gama describe su "ditosa pátria” al rey de Malindi: "Eis aqui, quase cume da cabeça / De Europa toda, o Reino lusitano, / Onde a terra se acaba e o mar começa” (3: 20).

Por lo tanto, estoy plenamente de acuerdo con Manuel Vásquez Medel cuando afirma que "pocas veces ha sido factor tan decisivo en una novela el aquí" (5). Para un cerebro como el del propio Ricardo Reis, "que siempre procura encontrar simetrías en las irregularidades del mundo” (230), la equis del quiasmo que forman las dos oraciones:

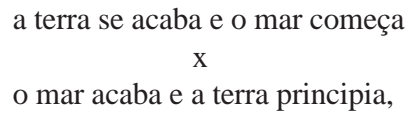

parece querer marcar el indeterminable lugar que apunta el deíctico aqui. De manera semejante, en los mapas que se nos deparan como un fanal redentor en las ciudades desconocidas donde nos perdemos, se señala con una cruz el lugar donde nos encontramos: you are here; Hier sind Sie; vous êtes ici. Sin embargo, la equis es también el signo de la incógnita y, tanto en lo que concierne a nuestra localización exacta en los laberintos topográficos de urbes ajenas como en el caso de la palabra aqui, es verdaderamente difícil ubicar el topos putativamente indicado por el shifter que abre El año de la muerte.

Si empezamos por tomar en cuenta la relación dialógica entre el verso camoniano y la frase de José Saramago, aqui se refiere por supuesto a la propia novela. Es decir: la perspectiva desarrollada en este texto se opone diametralmente a la del gran poeta renacentista. Citando el mismo verso de Camões para denominar el destino del viaje que hace uno de los personajes de Balada da praia dos cães, desde la desembocadura del Guadiana a la "otra punta del mapa” de Portugal, el escritor neo realista portugués José Cardoso Pires, contemporáneo de Saramago, describe al autor de Os Lusíadas como “aquele marquês que só via para um lado” (204), aludiendo de este modo tanto a la óptica imperialista del poeta como al conocido hecho de que ese genio poético absoluto, como lo ha llamado Saramago, era tuerto.

Ahora bien, la frase inaugural de El año de la muerte constituye obviamente una inversión directa de esta ciclópea mirada hacia el Atlántico. La equis quiásmica desempeña, en realidad, una función doble. Por un lado, designa un repliegue hacia 
el interior de la novela misma, es decir, la autorreferencialidad que se destaca como el estereotipo más reconocible de la modernidad literaria. Por otro lado, implica una negación de índole contestataria, representando sinecdóquicamente la subversión de las autoritarias "verdades históricas," subversión en la cual, como el propio Saramago lo sugiere, se resume discutiblemente todo su proyecto novelístico desde la publicación de Levantado do Chão: "quando sabemos que a História não só é parcial como é parcelar [...] porque é que a literatura não há-de ter também a sua própria versão da História?”. ${ }^{1}$ Como epítome de esta revisión de la 'Historia', podría aducirse el não con el que el protagonista de História do Cerco de Lisboa-el corrector de una crónica epónima-reemplaza el sim que representa presumidamente la monótona y reiterada legitimación del poder por la historiografía vigente. Todo sucedería, pues, como si la equis del quiasmo que inaugura El año de la muerte efectuara el movimiento de tachar esa autoridad epistémica. Para servirme de la sólida descripción que ofrece el eminente filósofo portugués Eduardo Lourenço, Saramago es, pues, "un arquitecto de grandes narraciones parahistóricas destinadas a subvertir la memoria y la mitología idealizadoras del pasado portugués” (Pessoa y Saramago 4). Citando la frase lapidaria que profiere la compañera del corrector al final de História do Cerco, el reino de este mundo pertenece a aquellos que tienen el talento de poner el no al servicio del sí, o que destruyen rápidamente el no para instaurar un sí (História do Cerco 330).

La equis surgiría, pues, como metáfora y metonimia convenientes de un doble y contradictorio designio en la obra de Saramago en general, y particularmente en El año de la muerte, propósito éste que abarca simultáneamente el autotelismo y el compromiso literario. Por ende, la sima especular abierta por la enmarañada y "borgeana" imbricación de referencias literarias que entrelaza el tejido de la novela aspira a transformarse precisamente en el vínculo entre el verbo y el mundo, el mundo entendido no como espectáculo sino como vivencia en toda su compleja y vulnerable perplejidad.

Tal como el hueco textual [le creux] a partir del cual, de acuerdo con Pierre Macherey, el texto literario se despliega hacia su exterior, el abismo autorreferencial en el centro de la novela de Saramago propasaría sus bordes textuales para intersectarse en última instancia con la propia historia. Es esta oscilación entre

\footnotetext{
1 La cita pertenece a una meditación más detallada presente en los diálogos entre Carlos Reis y Saramago: "Acho que [a ficção] tem toda a legitimidade [para] dar uma nova versão dos factos de que temos conhecimento por uma certa versão deles. Evidentemente que aquilo que nos chega não são verdades absolutas, são versões de acontecimentos, mais ou menos autoritárias, mais ou menos respaldadas pelo consenso social ou pelo consenso ideológico ou até por um poder ditatorial [...] Não sei porque é que, chegando o momento em que determinado escritor passaria por certo facto ou episódio, deveria aceitar como lei inamovível uma versão dada, quando sabemos que a História não só é parcial como é parcelar. Noutros termos: porque é que a literatura não há-de ter também a sua própria versão da História?” (Reis 86-7, el énfasis es mío).
} 
autorreferencialidad y empeño político la que subyace en la estructura de $E l$ año de la muerte y que pretendo abordar en este ensayo.

Como menciono arriba, una parte integrante de la noción de compromiso que emerge en El año de la muerte es la subversión de una determinada y autoritaria narración del papel formativo que desempeña supuestamente el Atlántico en la consolidación de la identidad y conciencia nacional portuguesa. En lo que sigue, propongo examinar detenidamente la compleja imbricación entre este proyecto revisionista y la resignificación de la visión atlántica (o del “imperialismo espiritual”) de Pessoa que efectua Saramago en la novela. Lo que resaltará en el curso de mi lectura es que esa revisión reproduce algunos de los rasgos más sobresalientes de la transformación dialéctica del imperialismo poético pessoano que elabora Pablo Neruda en "Lámpara marina". Por último, tanto en Neruda como en Saramago se vislumbra lo que podría designarse como un "atlanticismo" orientado hacia el sur, cuyo objetivo es solidarizar a los pueblos peninsulares con los de América (y África) y que constituirá la trama de Balsa de piedra, la novela que publica Saramago inmediatamente después de El año de la muerte.

Como se ha sugerido, esta conocida novela "pessoana" de Saramago relata una suerte de crónica de una muerte anunciada: la de un personaje cuya existencia literaria ya era de sobra conocida antes de su aparición entre las portadas del libro (Vásquez Medel 7). Se trata del más sobrio y horaciano, del más "extraterrestre" (según Eduardo Lourenço) de los heterónimos de Pessoa. Sus rasgos esenciales ("lo que es necesario para que se sepa quién dice ser"), tal como los inscribe en el libro de las entradas del hotel lisboeta donde se hospeda, reproducen el diáfano retrato de su álter ego de papel que nos ha legado el poeta mismo: "nome Ricardo Reis, idade quarenta e oito anos, natural do Porto, estado civil solteiro, profissão médico, última residência, Rio de Janeiro, Brasil, donde procede, viajou pelo Highland Brigade” $(O$ ano da morte 21). Lo que ocasiona el viaje transatlántico del poeta neoclásico -y que de hecho desencadena toda la acción de la novela- es el telegrama que recibe del heterónimo futurista de Pessoa dando la noticia de la muerte de su creador: “Fernando Pessoa faleceu Stop Parto para Glasgow Stop Álvaro de Campos”(80). El proyecto novelístico (que se desarrolla inevitablemente como una ficción sobre una ficción) tendrá así como objetivo la resolución narrativa del problema: "descubrir el resto", "lo oculto" en este "principio [de] confesión [o de] autobiografía íntima” que confía Ricardo Reis al registro del Hotel Braganza (21).

Saramago ha resumido de forma admitidamente lúdica (o en plan de "chiste" [piada]) la relación que busca establecer entre sus narrativas y los epígrafes que suelen encabezarlas: "é como se eu escrevesse os romances para justificar, para arredondar ou para desenvolver aquilo que já está contido numa epígrafe” (Reis 122). El más tajante de los tres epígrafes que inauguran El año de la muerte es el 
célebre verso de Ricardo Reis que el novelista ha calificado de rotunda "idiotez", considerándolo, además, como una de esas manchas [nódoas] que todos llevamos en la vida: “Sábio é quem se contenta com o espectáculo do mundo” (Reis 160). De acuerdo con la explicación del escritor, El año de la muerte sería así una dilatada refutación de la presunta "sabiduría” contemplativa que el epígrafe, como sinécdoque de la tendencia literaria encarnada por Reis, aparentemente respalda. Saramago hace que Ricardo Reis regrese a la patria precisamente en vísperas de 1936, "el año del huevo de la serpiente”, es decir, en el que se prepara el triunfo efímero pero devastador del fascismo en Europa: "Es como si yo estuviera diciendo a Ricardo Reis: ‘¿Pues tú te crees que la sabiduría es contentarse uno con el espectáculo del mundo? Pues entonces aquí tienes el espectáculo del mundo y dime si se puede llamar sabiduría a contentarse sentado mirando el espectáculo”" (Halperín 70). Esta observación remite, por otro lado, a la definición que hace el novelista del compromiso y deber ético.

En varias entrevistas, Saramago ha venido definiendo su labor literaria como una ampliación de su papel y responsabilidad como ciudadano. Para él, las dos condiciones, la de ciudadano y la de escritor, son inseparables (Reis 54). Como novelista, Saramago se interesa sobre todo por los sucesos mundanos y, consecuentemente, el objetivo principal de su actividad como escritor es encajar su producción literaria en la vivencia social, encuadrarla con su conciencia política, para que su escritura "tenga algún sentido en el mundo que estamos viviendo, que no sea algo que está al margen” (Halperín 13). Al mismo tiempo, tanto la estructura y disposición de ese campo extraliterario como la forma singular que asume la responsabilidad ética del escritor se elaboran a partir de una determinada comprensión de la historia y del funcionamiento y organización de las fuerzas sociales: "O marxismo serve-me para compreender o mundo de um modo que faz todo o sentido" (Reis 78), afirma Saramago. Y en conversación con el periodista francés Bernard Pivot aduce esta frase memorable: "Padezco de algo que puede llamarse el comunismo hormonal [...] que me impone una obligación ética” (citada en Halperín 14-15).

En El año de la muerte, quien desafía a Reis para asumir el compromiso con lo que sucede en el mundo es el fantasma de Pessoa, deambulando por un espacio lisboeta que parece circunscribirse a la onírica topografía de la ciudad que han trazado con melancólica insistencia los versos del propio poeta. Al comentar la correlación entre los regímenes de fuerza y la intensificación de la producción intelectual (defendida por el periodista y ex futurista António Ferro, quien asumió la dirección del Secretariado de Propaganda Nacional bajo Salazar en 1933), Pessoa caracteriza las Odas de Ricardo Reis como: 


\begin{abstract}
una poetización del orden [...] la agitación de los hombres es siempre vana, los dioses son sabios e indiferentes, viven y se extinguen en el mismo orden que crearon [...] Por encima de los dioses está el destino. El destino es el orden supremo, orden al que los propios dioses aspiran. (Saramago, El año de la muerte 270)
\end{abstract}

Más tarde, al estallar la guerra civil de España, las implicaciones políticas de este panegírico del orden se aclararán: "Les beaux esprits se rencontrent, dizem os franceses, gente sobre todas arguta. Falara Ricardo Reis da necessidade de defender a ordem, e agora veio declarar o general Francisco Franco, em entrevista ao jornal O Século, português, Queremos a ordem dentro da nação” (O ano da morte 376).

A la pregunta que hace Reis respecto del papel de los hombres frente a este implacable destino, Pessoa contesta como si durante su retorno póstumo al reino de este mundo se hubiera acercado a la visión política de Saramago: "Perturbar el orden, corregir el destino [...] Para mejorarlo o para empeorarlo, es igual, lo que hay que hacer es impedir que el destino sea el destino" (El año de la muerte 270). La caracterización que adelanta Pessoa de la producción poética de su heterónimo constituye, al mismo tiempo, una autocrítica, no tanto de su propia poesía (aunque necesariamente también lo sea), sino de su postura hacia el "fajismo de cátedra -pedagógico y doctrinario", como le llamó Unamuno en 1935 a la dictadura “bélicoescolástica” instaurada en 1926 (Unamuno 216), a la que se vincularía Salazar dos años más tarde y que alrededor de 1932 obtendría la inicial denominación oficial de Estado Novo.

En su célebre apología de la dictadura publicada en 1928 ("O Interregno -Defesa e Justificação da Ditadura Militar em Portugal”), Pessoa designa como fraude todo régimen político portugués que no sea la monarquía absoluta. Puesto que "la democracia moderna es la sistematización de la anarquía" (Páginas de pensamento político 2: 53), o sea la legitimación del desorden y del error, una vez que se reconoce el equívoco y se adquiere la conciencia del fraude como fraude, el único recurso que se plantea para restaurar la "política de la verdad” (cuyo ejemplo Pessoa vislumbra en el carácter ascético del "hombre de ciencia, de trabajo y de pocas palabras” que es el excepcional jefe de estado portugués [Páginas 2: 73, 66]) es la fuerza:

Se [...] temos que apelar para a força para governar o país, a solução está em apelar clara e definidamente [...] para aquela força que possa ser consentânea com a tradição e a consecução da vida social. [...] Quando se estabelece uma ditadura nos países latinos, estabelece-se uma disciplina. (Páginas 2: 57, 75, 73)

Sería difícil encontrar un ejemplo más contundente de uno de esos autores que, a lo largo del siglo pasado, con más o menos obediencia o más o menos servilismo, 
han prestado servicio a "ciertos regímenes políticos de tipo autoritario" (Reis 156). Entre ellos habría que incluir al propio Unamuno, cuya adhesión a la Junta Gubernativa de Burgos en nombre de la salvación de la civilización occidental define el gárrulo narrador de El año de la muerte como "una herida vergonzosa que se oculta” (El año de la muerte 308).

Otro ejemplo de un autor que ha obrado en pro de la dictadura, por ventura insólita, inesperada aún, sería el de Paul Valéry, que redactó, a pedido de António Ferro, el prólogo a la traducción francesa (publicada en 1934) de su adulatoria biografía del gran hombre: Salazar: o homem e a sua obra (1933). En términos que recuerdan al ecuánime distanciamiento que profesa Ricardo Reis frente al espectáculo del mundo, Valéry admite en el párrafo que abre su corto ensayo ("L’idée de la dictature") su voluntaria (o voluntariosa) ignorancia respecto a la "cosa pública”. Entre la amalgama de fuerzas e ideas de la que huye el poeta francés se destaca exactamente el aspecto teatral. Y es el eventual efecto de ese componente "espectacular" lo que, supone él, ha motivado a "M. António Ferro" a solicitarle la redacción de esas escasas líneas de préambulo (Valéry, Oeuvres complètes 970).

Reiterando aparentemente el argumento que desarrolla Pessoa en "Interregno" acerca de la necesidad de recurrir a la fuerza a fin de suprimir el fraude político, Valéry sugiere que el dictador frecuentemente se siente forzado a usurpar el poder, "comme le spectateur d'un jeu trop mal joué se sent une fureur de bousculer l'incapable et de prendre sa place” (975). Obsérvese de pasada que este hipotético espectador, que decide no sólo intervenir sino cambiar el espectáculo que visualiza, se presenta como el reverso del sabio (¿poeta?) contemplativo de Ricardo Reis, reproduciendo algunas de las características más marcadas del compromiso político por el que, en última instancia, aboga Saramago en su novela pessoana. No obstante, si la meta del proyecto novelístico de Saramago, y de su militancia por extensión, es reivindicar los entes “dispensables" que, desde una determinada óptica, constituyen la condición de posibilidad de la historia como proceso pero que la historia desecha como narración, el dictador, de acuerdo con Valéry, una vez alcanzado el poder, se convierte en la encarnación única y privilegiada del espíritu, algo así como el “destino portugués” en el que el Ferro “tonto” de El año de la muerte acaba por transformar la irrisoria figura de Salazar (334). De manera semejante, a los ojos de Pessoa, el rasgo que fundamenta el prestigio de Salazar como hombre de estado es la calidad que lo distingue radicalmente de su pueblo:

Salazar, [...] ao contrário [...] dos portugueses vulgares, incapazes de pensar claramente e de querer firmemente, um espírito excepcionalmente claro, uma vontade omnimodamente forte [...] Logo desde o princípio, Salazar marcou, e depois acentuou, uma firmeza de propósito e uma continuidade de execução de 
um plano [...] O seu prestígio reside nessa formidável impressão de diferença do vulgo português. (Páginas 2: 66-67)

Si en este texto inédito, escrito tres o cuatro años después de la publicación de su “defensa y justificación” de la dictadura, Pessoa pretendía revisar la evaluación demasiado partidaria que había desarrollado en el opúsculo, Valéry es decididamente menos ambivalente en su retrato "idealizado" del dictador.

Para el poeta francés, el ejercicio ilimitado de la voluntad dictatorial, la imposición unilateral del pensamiento en el campo proteico de lo social, depende de la reducción al estatus de objetos o de materia inerte de aquellos que la historia vigente tiende a relegar, de acuerdo con Saramago, al desperdicio y al olvido. ${ }^{2}$ No está muy lejos la concepción abstracta que elabora Valéry del poder dictatorial, y que el propio Salazar nunca se cansó de reiterar a lo largo de su extenso liderazgo, aunque de forma quizás más modulada, como por ejemplo en esta nota oficiosa de abril de 1935, en la que elucida la política de represión del régimen:

O Estado será um pensamento em acção, pelo que se hão-de fatalmente defrontar [...] conceitos diversos do homem, de Estado, de Nação, de poder, de liberdade, de fins humanos [...] Pelos motivos expostos nos convinha a nós ir limpando o terreno de todos os elementos cuja atitude doutrinal não fosse de si defesa suficiente contra a invasão dos novos bárbaros. (32)

El hecho es que, aparte de una momentánea y sorprendente identificación con lo que llama la jouissance extraordinaire de hermanar el poder y el pensamiento, de hacer ejecutar por todo un pueblo lo que un individuo ha concebido, modificando por sí solo y durante un largo período el carácter de una nación, aparte de comentar sumaria y convencionalmente la "modernidad” de este tipo de personalización del poder, Valéry no llega a definir abiertamente su postura política frente a la dictadura como sistema político (978-79).

En Portugal, por otro lado, la actividad del ministro de propaganda de Salazar alrededor de la publicación de la revista Orfeu, así como su asidua frecuentación de cenáculos modernistas, le posibilitó establecer diversos contactos que le permitirían asegurar la participación en la labor de propaganda del régimen de varios artistas e intelectuales, seducidos a la vez por el carisma del personaje del antiguo poeta futurista y la perspectiva de encomiendas oficiales. Es evidente que la participación de Valéry no alcanza este nivel. Sin embargo, al aceptar la solicitud de António Ferro, Valéry -tal como el Pessoa del “Interregno” y el Unamuno que se puso a disposición

\footnotetext{
2 "Un dictateur [...] demeure seule volonté libre, seule pensée intégrale [...] en présence d’un nombre immense d'individues réduits indistinctement, -quelle que soit leur valeur personnelle, -à l'état de moyen ou de matière [...] que l’intelligence peut prender pour son objet” (Valéry 975).
} 
de los falangistas- se revela hasta cierto punto cómplice de la instrumentalización del ser humano que se describe arriba. Al mismo tiempo, Valéry se instrumentaliza a sí mismo, o sea, se ofrece como uno de los "medios" (o "materia”) al servicio de la propaganda salazarista, surgiendo así como la verdadera antítesis del modelo de compromiso político que se propone implícitamente en El año de la muerte, una especie de compromiso al revés que, como alega el novelista portugués, a lo largo del siglo pasado ha llevado a ciertos escritores a ponerse "com mais ou menos obediência ou com mais ou menos subserviência ao serviço [de] certos regimes políticos de tipo autoritário” (Reis 156).

Para servirme de las palabras del ubicuo narrador de El año de la muerte sobre la memorable y rememorada respuesta del rector de la universidad de Salamanca al oxímoron “necrófilo” y brutal del general Millán Astray (“¡Viva la muerte!”): lo que separa tanto a Unamuno como a Pessoa del poeta de Le cimetière marin es el hecho de que los dos vivieron "el tiempo suficiente para vislumbrar su error" (El año de la muerte 308). En cuanto a Pessoa, como lo demuestra nítidamente la lectura de cualquiera de los varios textos inéditos escritos en el último año de su vida, la mayoría de los cuales salieron a la luz sólo después de la caída del Estado Novo en abril de 1974, su opinión acerca de Salazar sufrió alteraciones considerables. En dos de tres poemas satíricos, compuestos, según consta, tres meses antes de su muerte y publicados por primera vez en junio de 1974 por Jorge de Sena, Pessoa desmantela con acérrima y tajante ironía el sinsentido altisonante del discurso oficial estadonovista: "A tua face de rosa / Tem o colorido esquivo / De uma nota oficiosa. / Quem dera ter-te nos meus braços, / Ó meu saldo positivo!” (Páginas 2: 84). Su blanco predilecto es, empero, la imagen del jefe como hombre providencial meticulosamente armada por la propaganda oficial: “António de Oliveira Salazar. / Três nomes em sequência regular [...] / António é António. / Oliveira [olivo] é uma árvore. / Salazar é só apelido. / Até aí está bem. / O que não faz sentido / É o sentido que tudo isto tem" (Páginas 2: 83).

En el texto que cito a continuación, también de 1935 y originalmente redactado en francés, todo parece suceder como si Pessoa retuviera como principal objetivo poner en cuestión la elogiosa evaluación que hace Valéry de Salazar. Así lo expresa Valéry:

Les idées exposées dans ce livre [Salazar] par M. Salazar ou qui lui sont attribuées me semblent parfaitement sages. Elles témoignent d'une réflexion profonde, élaborée par un esprit qui ressent la grandeur du devoir qu’il s’est assigné. (Valéry Oeuvres complètes 970)

Contrástese este juicio con la "síntesis cruel y por ventura exacta" (Medina 229) que del tirano construye aquí el poeta de Mensagem: 
Inteligente sem maleabilidade, religioso sem espiritualidade, ascético sem misticismo, este homem é de facto um produto de uma fusão de estreitezas: a alma campestremente sórdida do camponês de Santa Comba [el pueblo de provincia del cual el dictador es oriundo] só se alargou em pequenez pela educação do seminário, por todo o inumanismo livresco de [la universidad de] Coimbra, pela especialização rígida do seu destino desejado de Professor de Finanças [...] Para governar um país como chefe, falta-lhe, além das qualidades próprias que fazem directamente um chefe, a qualidade primordial -a imaginação. (citado en Medina 11)

Sería posible de este modo sugerir que el espectro “subversivo” de Fernando Pessoa que inventa Saramago es, en el fondo, cabalmente histórico, es decir, del todo consecuente con el intransigente y acérbico personaje que en los postreros meses de su vida se revela progresivamente más crítico frente al régimen salazarista. Esta intransigencia sólo vendrá a conocerse póstuma o fantasmagóricamente, o sea en los textos inéditos de Pessoa publicados después de abril de 1974 y a través de la caracterización de su personaje en El año de la muerte.

Por otro lado, el Pessoa "fantasmagórico" de El año de la muerte, el que menosprecia al Secretario de Propaganda salazarista como un "tonto", y que posee el don profético de plantear como "hipótesis" -y casi con dos meses de antelación- el "no"” que lanzará Unamuno después de la "muerte” de Ricardo Reis (el 12 de octubre de 1936), es también una de las múltiples máscaras retóricas de las que dispone el omnipresente autor de la novela. De acuerdo con ese mismo autor, no es tanto su llamado "comunismo hormonal" lo que constituye el aspecto más subversivo de su narración, sino su ubicuidad, su proclividad a la digresión verborrágica y laberíntica:

Creio que a subversão maior [...] é a da aceitação muito consciente do papel do autor como pessoa, como sensibilidade, como inteligência, como lugar particular de reflexão, na sua própria cabeça. É o lugar do pensamento do autor, em livros que se propõem como romances e como ficções que são [...] eu sou aquele que faz o romance. E quero que isso se veja e se saiba. (Reis 97)

El fantasma pessoano que recorre las páginas de la narrativa es pues uno de esos lugares privilegiados de reflexión autorial, el foco de inteligencia (central intelligence) que era la metáfora panóptica de la voz narrativa que solía utilizar Henry James, la señal o autógrafo del creador, la "faja” que proclama en alta voz que ha pasado por

\footnotetext{
3 Como se sabe, la famosa elucubración del catedrático vasco empieza con esta frase vibrante: “Callar, a veces, significa mentir". Para el narrador de $O$ ano da morte, como hemos visto, "valió la pena que Miguel de Unamuno hubiera vivido el tiempo suficiente para vislumbrar su error, sólo para vislumbrarlo, porque no lo enmendó por completo" (El año de la muerte 308). Un poco más adelante, leemos: "El sí y el no de Miguel Unamuno [sic] conturban a Ricardo Reis” (310).
} 
este mundo "um homem que se chamou José Saramago" (Reis 98). El Fernando Pessoa de Saramago es, por otros términos, la personificación de la equis, del shifter (aqui) que abre El año de la muerte y funciona como sinécdoque de la negación o corrección ficcional de la historia respaldada de una forma u otra por el consenso social o el consenso ideológico o, como es seguramente el caso del Portugal de 1936, por decreto dictatorial. Para reiterar el juicio de Saramago: “Acho que a literatura tem toda a legitimidade [para] dar uma nova versão dos factos de que temos conhecimento por uma certa versão deles” (Reis 86).

Desarrollando una dialéctica de considerable sutileza, Saramago resucita al coloso del modernismo portugués a fin de inscribir, por medio de su presencia y en el mero centro de su obra, el repudio contundente a uno de los "dogmas" más paradigmáticos del modernismo: el que prescribe la "muerte” o ausencia del autor:

Quando digo que a subversão é essa [la de introducir la presencia del autor en el texto], isso resulta dessa espécie de novo dogma que se instaurou nas últimas dezenas de anos, segundo o qual a presença do autor é incómoda; que aquilo que o autor é não tem que ser considerado no momento de analisar o livro e sobretudo porque se supõe que o autor terá todo o cuidado em não estar presente no livro. (Reis 97)

La marca ubicua del autor en el libro es, por fin, el nexo donde se funden (y se confunden) el fondo y la forma, o, si se prefiere, la ética y la estética. Una vez más, por obra de otra sutil y compleja operación dialéctica, Saramago se sirve de uno de los procedimientos más característicamente modernistas (la autorreferencia) para superar y cancelar, en última instancia, la subjetivización de la realidad, o lo que los miembros de la Escuela Crítica de Constanza han denominado Entrealisierung, la pérdida de lo real, o de su efecto, como aduciría Roland Barthes. No sería del todo erróneo sugerir por ende que Saramago logra reproducir en su ficción la hermenéutica de acuerdo con la cual Fredric Jameson convierte el individualismo prototípicamente modernista en una forma latente de colectivismo utópico, en una alegoría de "la transformación del mundo mismo, y por tanto de lo que llamamos revolución” (135-36).

En un ensayo sobre el modernismo que se ha convertido en un clásico desde su publicación hace casi dos décadas, Perry Anderson apunta precisamente a "la proximidad imaginativa de la revolución social” como una de las tres coordenadas decisivas cuya confluencia produce el conjunto de condiciones socio-políticas que posibilitan la emergencia del modernismo artístico(326). Varios críticos, en particular

4 Saramago alega: “A veces yo digo que, si pudiera, por lo menos en mis libros les pondría una faja que dijera ‘¡Ojo!, este libro lleva una persona adentro’. Y esa persona es el autor” (Halperín 66). 
Raymond Williams, han referido la ambivalencia política a la que alude Anderson, es decir, las distintas y opuestas orientaciones que los movimientos modernistas y de vanguardia suelen adoptar, por un lado, hacia tendencias socialistas o incluso radicales y revolucionarias, y por otro, en el sentido de una firme identificación con nacionalismos de derecha y aun derivados en larga medida del fascismo italiano y alemán (58).

En 1936, la experiencia de inestabilidad y el sentimiento de precariedad, provenientes de lo que Anderson designa como la profunda ambigüedad con relación a los eventuales resultados del derrumbe del viejo orden, se concentran y exacerban para el mundo hispanohablante en la guerra civil española. Como lo afirma Salazar en agosto de 1936, "o comunismo está a travar na Península uma formidável batalha de cujo êxito dependerá em grande parte a sorte da Europa” (2: 213). No es obviamente éste ni el lugar ni el momento propicio para volver a examinar en detalle la conocida y enredada historia del inestimable impacto producido por el combate reñido entre la República española y el franquismo en el desarrollo de una poesía política o revolucionaria en América Latina. A guisa de ilustración, aduciré, pues, la consabida y, de cierta forma, paradigmática “confesión” de Pablo Neruda: "Aunque el carnet militante lo recibí mucho más tarde en Chile, cuando ingresé oficialmente al partido, creo haberme definido ante mí mismo como comunista durante la guerra de España” (Confieso que he vivido 168). De modo semejante, César Vallejo declara que "la causa de la República española [...] es la causa del mundo entero" (171). Consecuentemente, tanto para Vallejo como para Neruda, lo que el poeta peruano designa como "la responsabilidad del escritor ante la historia" (173) consiste precisamente en el rechazo e inversión de la estereotípica postura antidemocrática del modernismo temprano que adopta Fernando Pessoa en 1915, la cual emblematiza de forma depurada su heterónimo horaciano:

O desenvolvimento [da "arte moderna” é] para uma interiorização cada vez maior [...] essa arte não é feita para o povo [...] Toda a arte que fica é feita para as aristocracias, para os escóis, que é o que fica na história das sociedades, porque o povo passa, e o seu mister é passar. (Páginas sobre literatura e estética 99,102)

Por el contrario, para Vallejo "los escritores libres están obligados a consustanciarse con el pueblo [...] y romper esa barrera secular que existe entre la inteligencia y el pueblo" (173). Del mismo modo, para Neruda la cuestión primordial reside en "la utilidad pública de la poesía”, en cómo “puede la poesía servir a nuestros semejantes [o] acompañar las luchas de los hombres (Confieso 171, 173). Las afirmaciones de Vallejo datan de julio de 1937. Dos años antes, Jorge Amado reproduce la definición de compromiso aquí propuesta por Vallejo: “O intelectual de hoje ou se compromete 
com o proletariado para a luta em reivindicação dos oprimidos ou defende com unhas e dentes a sociedade capitalista que agoniza" (citado en Ciacchi 104). ${ }^{5}$

Que esta perspectiva de la práctica y el compromiso políticos se inserte en un internacionalismo radical lo demuestran tanto las declaraciones de Neruda y Vallejo citadas arriba como, por ejemplo, la escena final de Jubiabá, la novela de Jorge Amado escrita en 1935, de la cual se quemarán en público centenares de ejemplares por considerarse subversiva. Al final de la novela, el protagonista Antônio Balduíno, finalmente concienciado tras su militancia sindicalista, levanta la misma mano con la que había derribado a un adversario alemán en el capítulo inicial para saludar a un marinero europeo:

E o negro Antônio Balduíno estende a mão [...] e responde ao adeus de Hans, o marinheiro [...] Adeus para todos, que ele fez a greve e aprendeu a amar todos os mulatos, todos os negros, todos os brancos, que na terra, no bojo dos navios sobre o mar, são escravos que estão rebentando as cadeias. (329)

Obviamente, el "egoísta” viaje transatlántico de Ricardo Reis surge como la negación directa de la ética y perspectiva internacionalista que esboza este gesto de solidaridad ("Um dia Antônio Balduíno partirá num navio e fará greve em todos os portos” [329]) - gesto éste que se une, además, no sólo al emblemático compromiso transatlántico de Neruda y Vallejo sino a a la "obligación ética” impuesta por el "comunismo hormonal” del que alegadamente padece Saramago.

En El año de la muerte, una de las configuraciones que adquiere paulatinamente "el problema” que se plantea al principio de la novela de "descubrir el resto" sobre el lacónico pasajero de la Highland Brigade, es decir, el significado ético y ontológico de los ocho meses adicionales de vida que otorga el novelista al heterónimo de Pessoa, podría resumirse en la adquisición de una cierta conciencia política o en el rechazo gradual de la postura aristocráticamente contemplativa que encapsula el epígrafe de Reis (“Sábio é quem se contenta com o espectáculo do mundo”). Una de las etapas cruciales de esta lenta evolución se da en el momento en que el poeta decide "ver con sus propios ojos [el] espectáculo" de la simulación de un bombardeo aéreo organizado por las autoridades estadonovistas a fin de "explicar a los moradores cómo deberán proceder y proteger sus vidas” (336). Con este afán de mirar de cerca el "escenario y los actores”, Reis empieza a invertir su distanciamiento frente a la dura represión que en noviembre de 1935 Getúlio Vargas había ordenado contra uno de los regimientos de Rio de Janeiro adherido a la revolución liderada por Luiz Carlos Prestes, al final de la cual, según el informe confidencial enviado

5 En el año de la ficticia muerte de Ricardo Reis, Amado fue detenido y posteriormente encarcelado bajo la acusación de haber participado en la llamada "Intentona Comunista" -la fracasada revuelta que ocurrió en noviembre de 1935 (pocos días antes del "verdadero" fallecimiento de Pessoa). 
por el embajador portugués a Salazar, "o Brasil podia acordar de uma hora para outra transfigurado em república soviética”. ${ }^{6}$

El itinerario hacia el compromiso político de Ricardo Reis pasa, así, por América Latina, invirtiendo y “retribuyendo" tanto el saludo de Antônio Balduíno como la solidaridad entre la península y el continente iberoamericano que reivindicarán Neruda y tantos otros escritores latinoamericanos:

Ricardo Reis [assistiu] de longe aos bombardeamentos da Urca e da Praia Vermelha, tão distantes que poderiam ser tomados como exercícios iguais a este, para adestramento dos pilotos e treino de fuga das populações, o pior foi terem os jornais no dia seguinte, terem dado notícia de mortos reais e feridos verdadeiros.

Como sucede a menudo en El año de la muerte, es imposible saber a ciencia cierta si el que habla es el locuaz y omnipresente autor-narrador o el propio Ricardo Reis. No obstante, dada la coincidencia no sólo con eventos inmediatamente coetáneos al "espectáculo" (el bombardeo de Badajoz por los franquistas, por ejemplo), sino con el ataque a los dos navíos revoltosos anclados en el Tajo que ocurrirá en septiembre del fatídico año, no sería del todo impertinente discernir en este episodio el despertar del mismo espíritu revolucionario que Salazar quiso menospreciar en sus comentarios sobre la intentona:

No espírito de simples marujos foi possível por insistente acção de desnacionalizados de todos os povos, pela campanha de jornais espanhóis e panfletos portugueses, pela influência contagiosa dos maus exemplos, lançar a idéia do auxílio internacional aos ‘camaradas’ vermelhos, juntando os próprios barcos aos deles. (2: 186-87)

Es como si Ricardo Reis esbozara aquí, sin completarlo, el gesto de alzar el brazo para saludar a los revolucionarios del otro lado del Atlántico. Obligado a vivir justo lo suficiente para poder contemplar cómo rompe la cáscara del tiempo la serpiente que, según Saramago, fue el año de 1936; inducido no sólo a vislumbrar, sino a reconocer y enmendar su equívoco político -llegando a sentir "una especie de rencor" contra las crueldades cometidas por las fuerzas de Franco (El año de la muerte 315) y a llorar "lágrimas absurdas" por la derrota de la revuelta de dos navíos de guerra (O ano da morte 411)-, el Ricardo Reis de Saramago (siguiendo una lectura insólita, absurda aun, basada nada más que en una feliz y aleatoria coincidencia onomástica) encontraría así el eco de su ficticia conversión política en la transformación real del otro Ricardo: el (Neftalí) Ricardo Reyes, mejor conocido bajo el seudónimo de Pablo Neruda.

6 Véase la carta de Martinho Nobre de Mello, Embajador de Portugal (6 de Marzo de 1936). 
La relación especular que quiero recalcar a partir de aquí entre las trayectorias de Ricardo Reyes/Pablo Neruda y de Fernando Pessoa/Ricardo Reis hacia el compromiso político se resume a este escueto esquema. La definición de Neruda como comunista resulta de sus experiencias durante la guerra civil española, o sea de la vivencia de la historia del ciudadano Ricardo Reyes. En El año de la muerte, por el contrario, la transformación política se opera en el espacio doblemente ficticio que ocupa el heterónimo pessoano dentro de las páginas de la novela. De este modo, los dos procesos se reflejan uno al otro de forma quiásmica, o sea, en una equis.

La referencia a Neruda se hace quizás menos injustificada si tomamos en cuenta que los versos inaugurales de "La lámpara marina" -escrito más o menos por la época en la que el chileno firmaba junto con Jorge Amado un folleto antisalazarista solicitando la liberación del líder comunista portugués Álvaro Cunhal (1953-1954)podrían fácilmente dirigirse al protagonista de El año de la muerte: "Cuando tú desembarcas / en Lisboa [...] no sabes que detrás de las ventanas / escuchan, / rondan / carceleros de luto [...] arreando presos a las islas [...] destinando los hombres a la sombra" (Las uvas y el viento 181). Un breve análisis comparativo entre "La lámpara marina” y Mensagem (1934) -un poema "nacionalista”, según el juicio del propio Pessoa, o, un "poema de exaltação nacionalista, dos mais belos que se tem escrito”, para citar la nota necrológica publicada en el Diário de Notícias en diciembre de $1935^{7}$ - elucidará el diálogo póstumo que establece implícitamente Saramago entre Pessoa y Neruda (Pessoa, Crítica 496).

Aunque los ideólogos del Estado Novo hayan tratado de servirse del supuesto imperialismo del poema para fines propagandísticos, Mensagem nunca cumplió esta función ideológica de forma apropiada (según Maria Irene Ramalho Santos 44). Para Santos, la cuestión primordial del poema tiene muy poco que ver con el imperio material. Se trata sobre todo de una estetización del imperio, del “imperio espiritual” de la poesía. O sea que el intento de Pessoa en Mensagem es la reconstrucción poética de los descubrimientos portugueses y de la fundación del imperio occidental (110-12).

\footnotetext{
Este poema épico modernista recibió uno de los premios de poesía distribuido por el Secretariado de Propaganda Nacional. En el mismo discurso en el que Salazar anuncia el premio también establece las nuevas reglas de censura. En una carta a Adolfo Casais Monteiro, Pessoa describe la nueva situación del escritor en Portugal con característica ironía: "Desde o discurso que o Salazar fez em 21 de Fevereiro deste ano [1935] [...] ficámos sabendo, todos nós que escrevemos, que [...] 'não se pode dizer isto ou aquilo' [...] 'tem que se dizer aquilo ou isto'. Em palavras mais claras, tudo quanto escrevemos, não só não tem que contrariar os princípios (cuja natureza ignoro) do Estado Novo (cuja definição desconheço), mas tem que ser subordinado às directrizes traçadas pelos orientadores do citado Estado Novo. Isto quer dizer, suponho, que não poderá haver legitimamente manifestação literária em Portugal que não inclua qualquer referência ao equilíbrio orçamental à composição corporativa (também não sei o que seja) da sociedade portuguesa e as outras engrenagens da mesma espécie” (Páginas de pensamento político 2: 80-1).
} 
Por otro lado, no sería particularmente difícil para los intelectuales orgánicos del régimen apropriarse de versos como estos: "Cumpriu-se o Mar, e o Império se desfez. / Senhor, falta cumprir-se Portugal!” (Mensagem 57). De acuerdo con una resignificación ultranacionalista, los versos constituirían no sólo una celebración de los descubrimientos portugueses sino que reiterarían el siguiente lugar común salazarista (sacado de un discurso de septiembre de 1935): "Somos sobretudo uma potência atlântica, presos pela natureza à Espanha, política e económicamente debruçados sobre o mar e as colónias, antigas descobertas e conquistas” (Salazar 79-80). De manera semejante, el verso ambivalente que cierra el poema, É a hora!, podría bien presentarse como una convocatoria a la juventud lusitana para emprender el absurdo proyecto de restaurar el Império Quinhentista en pleno siglo xx.

Volviendo momentáneamente a la negación de una cierta visión atlántica encapsulada en la frase inaugural de El año de la muerte, podemos ahora aclarar que lo que rechaza implícitamente la primera oración de la novela no es la épica camoniana en sí, sino una determinada (o "sobre determinada”) lectura de la obra. Sobran ejemplos de esta apropiación salazarista de la figura de Camões, de modo que me serviré de una referencia puntual para ilustrar este aspecto. Se trata de la observación que hizo en octubre de 1944 el cardenal Manuel Gonçalves Cerejeira, patriarca de Lisboa y uno de los más leales defensores del Estado Novo, de regreso de una larga gira por las colonias portuguesas. Según el prelado, el sentido de "toda a nossa História colonizadora -'dilatar a Fé e o Império-’” ya lo había definido Camões (Boletim Geral das Colónias 20: 267). Su Eminencia manifiesta con esta afirmación su adherencia a la corriente hermenéutica dominante del estadonovismo referida arriba, parte integrante de lo que puede denominarse la mística imperial salazarista.

En 1972, tres años después del fallecimiento del dictador y prácticamente en vísperas de la caída del régimen, esta lectura ideológica del poema épico ya se había convertido en rotunda banalidad. No obstante, en ese mismo año, nos aseguran sin la más ligera ironía que

Os Lusíadas são a brônzea imagem dum povo que sendo geográfica e polìticamente europeu, instintiva e deliberadamente assumiu na hora própria, o seu destino de expansão marítima [...] [são] a gesta de um povo que, pequeno de mais na extensão territorial que lhe coube, teve de criar uma epopeia à medida do seu sonho. (Trigueiros 183)

Afirmando la historicidad de la evocación de un nuevo reino edificado "entre gente remota” en la primera décima de Os Lusíadas, el historiador estadonovista António Banha de Andrade insiste en la importancia del papel del mar, el cual no se puede reducir de ninguna forma a un mero "devaneo poético”, porque en realidad 
constituye "una de las más notables constantes históricas del Espacio Portugués" (49). En suma, Camões no sólo "encarna lo que en el portugués hay de europeo y que, paradójicamente, lo lanza para fuera de Europa”, sino que demuestra una profunda comprensión de la "opción histórica” lusitana, fijando terminantemente "la concepción oceánica como un imperativo, a partir del Infante D. Henrique [...], el nuevo itinerario [roteiro] de la política portuguesa” (Trigueiros 183). ${ }^{8}$

No es de sorprender, por tanto, que en el libro de António Ferro Salazar sostenga que "as nossas Colónias deveriam ser as grandes escolas do nacionalismo português” (150). Seis años más tarde, defendiendo la neutralidad portuguesa justo en el momento en que el continente europeo estaba a punto de hundirse en un asolador conflicto global, Salazar describe la posición marginal y marginada del país frente a lo que él, con su habitual provincianismo, caracteriza como "desasosiego general”, una cuerda y voluntaria relegación del rectángulo lusitano “a um canto da Europa, quási desligado dela e projectado ousadamente sôbre o mar, país atlântico por excelência", dotado de una "feição atlântica" y empeñado en una actividad colonial definida por el "heróico esforço de Portugal criador de impérios" (Boletim Geral das Colónias 15: 20, 25). He aquí la variación ibérica del eurocentrismo que Derrida, sin servirse por supuesto de este término, considera la familiar y repetida "autobiografía de Europa", la narrativa que describe repetidamente al continente "comme une avancée -l'avant-garde de la géographie et de l'histoire" (50)-precisamente una de "las mitologías idealizadoras del pasado portugués" que en El año de la muerte se procura subvertir.

Entre todos los posibles ejemplos deeste "viejo discurso ejemplary ejemplarista", Derrida elige el de Paul Valéry ("La crise de l'esprit”) precisamente porque lo considera tan típico o arquetípico como cualquier otro (70). La metáfora que utiliza Valéry para definir la ascendencia cultural de Europa ("une sorte de cap du vieux continent” [1004]) nos remite a los versos de Camões que plasman al reino lusitano como la "cumbre" de la cabeza de toda Europa. Tanto la imagen camoniana como la metáfora de Valéry retornan en el poema inaugural de Mensagem: "A Europa jaz [...] / De Oriente a Ocidente jaz, fitando [...] / Fita, com olhar esfíngico e fatal, / O Ocidente, futuro do passado. / O rosto com que fita é Portugal” (21). ${ }^{9}$

8 Véase también Theophilo de Andrade 137.

9 La prosopopeya reproduce obviamente el "discurso atlántico" del mandatario portugués; en ella reverbera además la imagen final del Ultimatum de Álvaro de Campos (Fernando Pessoa), publicado por primera vez en 1917 en el primer y único número de Portugal Futurista. En la última línea del célebre manifiesto, el heterónimo futurista de Pessoa proclama la toma inminente por parte de la civilización europea de un rumbo vagamente nietzscheano: "na barra do Tejo, de costas para a Europa, braços erguidos, fitando o Altântico e saudando abstratamente o Infinito!” (129). La figura del vate de brazos extendidos a la orilla del mar surge como una suerte de equivalente humano del padrón con el que se marcaban, en nombre de Dios y del rey, los territorios desconocidos a los que arrivaban las llamadas carabelas de Cristo. 
Para volver a la discusión del pensamiento político del gran poeta modernista portugués, Pessoa entiende el imperialismo poético como "a realização em espírito [d]aquilo que realizámos outrora em corpo”, considerando su construcción, en los apuntes que redacta sobre la primera guerra mundial durante la misma época (1916-18):

A cousa que mais urgentemente se impõe hoje em Portugal, [...] grande obra anticristã [...] obra pagã, obra anti-humanitária, obra de transcendência e elevação, feita através daquela crueldade para com nós próprios que o espírito de Nietzsche, num momento lúcido, viu ser a base de todo o sentimento de império. (Páginas de pensamento 1:141)

La figura más reconocible de este imperialismo anticristiano es posiblemente la del personaje poético de "Ode Marítima” en el apogeo de su evocación de esos "Portugueses atirados de Sagres / para a aventura indefenida, para o Mar Absoluto para realizar o Impossível!” (Poesias de Álvaro de Campos 176). Es importante insistir aquí en que, en las meditaciones redactadas durante este período, Pessoa concibe los descubrimientos como resultado de un impulso fundamentalmente pagano, surgidos no de la evolución del cristianismo sino, por el contrario, "duma aplicação de parte do espírito cristão a pontos anti-cristãos” (Páginas 1: 139). En uno de los momentos culminantes en "Ode Marítima” de esa evocación de los descubrimientos desprovista de toda "noção da moral" y humanitarismo, de los descubrimientos como expresión de una crueldad sublime -y en un gesto de identificación masoquista que es simultáneamente el signo de la inmensa distancia que separa su "estática, regrada e revista” época del tiempo mítico que intenta conjurar-, el poeta ofrece su "ser ciclónico e atlântico" a la rabia desmedida de esos "Homens que erguer[am] padrões, que de[ram] nomes a cabos!": "Crucificaime nas navegações / E as minhas espáduas gozarão a minha cruz!” (Poesias de Álvaro de Campos 177-178). El significado de la cruz de la Orden de Cristo que ornaba famosamente las velas de las naves del Infante se reniega, se tacha en esta imagen. La cruz se convierte en su propio y perentorio repudio. La cruz que encarna la persona poética simboliza así el rechazo total del cristianismo, la personificación del Anti-Cristo de Nietzsche. No podría ser más distinta la visión "imperialista” de Pessoa del mezquino y santurrón expansionismo abogado por los estadonovistas.

Eduardo Lourenço juzga el uso y abuso del profetismo tropológico y del nacionalismo idiosincrático de Pessoa como legitimación de un "cruzadismo voltado todo para o passado", sumamente innoble, como un sinsentido literario (Labirinto da Saudade 123). Al contrario de Santos, para quien Mensagem representa una negación mallarmeana de un imperialismo decadente y "materialista” en favor de un orden poético o "espiritual”, Lourenço insiste en que, si Pessoa aspira de hecho 
a "suprimir" el particularismo histórico-empírico, hay que concebir esta "autodisolución” orientada hacia el futuro en términos inequívocamente políticos. Según el filósofo portugués, este momento futuro se produciría a través de la "ascensión y trascendencia" [ascensão e transcenção] de la particularidad, tras un suicidio sublime de toda personalidad que posibilitaría la emergencia de una época de impersonalidad verdaderamente universal y fraternal (Labirinto da saudade 11519). En la concepción pessoana del porvenir de la nación, Portugal retrazaría el itinerario histórico del "imperio deshecho" con el objetivo de alcanzar, en última instancia, "la otra orilla", una dimensión atemporal en la que lo histórico se reduciría a la prefiguración de un futuro por venir (Mitologia da Saudade 147).

Si esta exégesis hegeliana tiene algún fundamento, la relectura que, a mi parecer, emprende Neruda del poema pessoano en "La lámpara marina" es relativamente consecuente con ella. La relación entre Mensagem y el poema de Neruda reproduciría así tanto el antagonismo entre el neoclasicismo poético de Ricardo Reis y el discurso novelístico de Saramago como la famosa inversión marxista del sistema hegeliano. A las preguntas que hace Pessoa: “Quando é a Hora?” (Mensagem 93), “Quem é que dorme a lembrar / Que desvendou o Segundo Mundo, / Nem o Terceiro quer desvendar?” (103), a su instancia a que "outra vez conquistemos a Distância- / Do mar ou outra, mas que seja nossa!” (73), a que iniciemos "a busca de quem somos, na distância / De nós" (99) y alcancemos la "Ilha próxima e remota [cuja] costa [...] se não pode encontrar" (101), Neruda parecería responder en la parte final del poema:

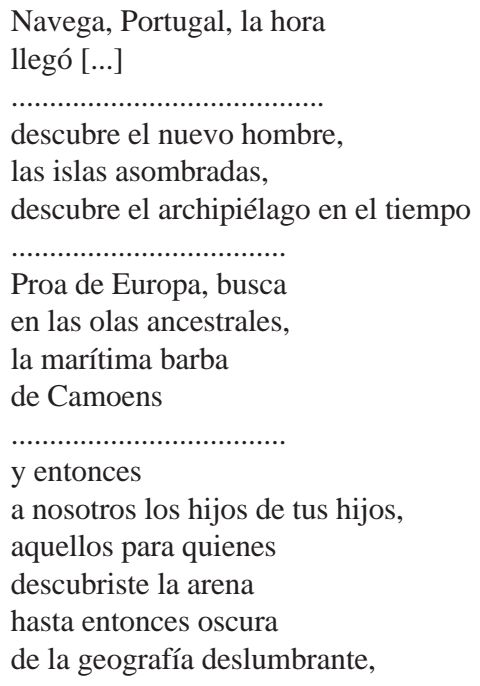




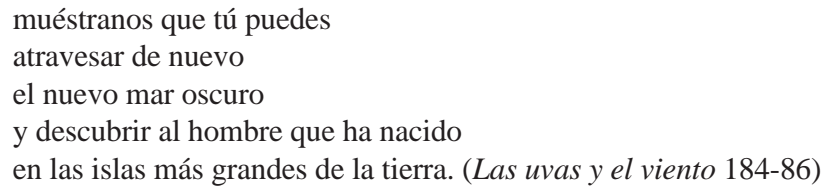

La recuperación “dialéctica” del pasado navegante de Portugal y, más particularmente, del "imperialismo espiritual" de Pessoa para esbozar una visión del futuro profundamente marcada por el marxismo, es evidente aquí.

Hasta cierto punto, las últimas líneas del fragmento repiten también el abrazo transatlántico con el que termina Jubiabá. Tampoco sería del todo impertinente sugerir que esto es precisamente la superación del atlanticismo pessoano que epitomiza la frase inicial de El año de la muerte, y que constituye probablemente el proyecto de la novela en su totalidad. De este modo, podría finalmente proponerse que la reescritura o subversión de esa transformación poética del imperio, así como de su mezquino reflejo en la mística imperialista del Estado Novo, se opera a través de una relectura del atlanticismo proveniente de y orientado hacia el sur que ejemplifican Amado, Vallejo y Neruda. Es importante subrayar que, a pesar de las marcadas e innegables diferencias entre el imperialismo de pacotilla de Salazar y el imperio espiritual del gran modernista portugués, lo que ambos mantienen en común es lo que Walter Mignolo define como una "hegemonía epistémica”: "así como es difícil hoy pensar modelos económicos ignorando el capitalismo, es asimismo difícil pensar modelos epistémicos ignorando el marco en el cual la epistemología moderna (de la modernidad euro-occidental) nos acostumbró a pensar el mundo” (60).

Es justamente el "otro cabo", para servirme de la metáfora que emplea Derrida para referir la diferencia cultural, la otredad, esa singularidad irreducible que "la cítara de oro de Camões" representa como el gigante Adamastor (quien se identifica en el centro de Os Lusíadas como “aquele oculto e grande cabo”), es esa “"otra cara' dominada, explotada, encubierta [...], laAlteridad esencial de la Modernidad”, como la denomina Enrique Dussel (1492 33), que en última instancia ni el imperialismo retrógrado del Estado Novo ni el imperio espiritual de Pessoa acatan. De acuerdo con el propio Saramago, es ésta la repudiación histórica que A Jangada de Pedra [La balsa de piedra] procurará corregir. En esta novela, que sigue inmediatamente a El año de la muerte, la Península Ibérica se separa del continente, transformándose en una isla que flota rumbo al sur, en la dirección de "uma utopia nova: o encontro cultural dos povos peninsulares com os povos do outro lado do Atlântico":

Uma visão duas vezes utópica entenderia esta ficção política como uma metáfora muito mais generosa e humana: que a Europa, toda ela, deverá deslocar-se para o Sul, a fim de, em desconto dos seus abusos colonialistas antigos e modernos, 
ajudar a equilibrar o mundo. Isto é, Europa finalmente como ética. (Saramago, Nobel Lecture)

Admitidamente, para el lector o lectora de este inicio de siglo, el discurso de responsabilidad en el que participaron Amado, Neruda y Vallejo, y con el que Saramago mantiene un vínculo "hormonal", nos recuerda inevitablemente a las acusaciones que se han impuesto a lo largo del siglo pasado a múltiples escritores e intelectuales en nombre de la Historia o de la Sociedad. Sin embargo, me gustaría vislumbrar en ese atlanticismo utópico que comparten Neruda y Saramago, y que aspira al encuentro entre los pueblos peninsulares y "el hombre que ha nacido en las islas más grandes de la tierra”, así como en la solidaridad enraizada en una "continuidad [o] coincidencia histórica" que discierne Vallejo entre "los pueblos iberoamericanos" y “el pueblo español en armas" (172), la conciencia incipiente de "otro posible relato de la modernidad que involucra a España, Portugal, los circuitos comerciales del Atlántico, el oro y la plata de las Américas, la esclavitud masiva y los Africanos en América además del casi exterminio de los Indígenas” (Mignolo 74). Si releemos los versos camonianos cuya orientación política y cartográfica invierte putativamente la primera frase de El año de la muerte, nos damos cuenta de que tanto esa inversión como el esbozo del otro relato de la modernidad existía ya ahí en potencia, exactamente en el encabalgamiento que separa "la cabeza" lusitana del continente europeo: "Eis aqui, quase cume da cabeça / De Europa toda, o Reino lusitano” (3: 20).

La novela pessoana de Saramago surgiría ahora no tanto como la corrección o revisión del atlanticismo de Camões, sino como una sutil y cuidadosa relectura de su épica, que revelaría finalmente una olvidada o escamoteada continuidad subterránea entre la idea profundamente elegíaca del imperio que ofrecen Os Lusíadas y "la visión dos veces utópica” que esboza El año de la muerte de Ricardo Reis.

\section{BiBLIOGRAFÍA}

Amado, Jorge. Jubiabá. São Paulo: Editora Record, 1978.

Anderson, Perry. "Modernity and Revolution". Marxism and the Interpretation of Cultures. Cary Nelson y Lawrence Grossberg, eds. Chicago: U of Illinois P, 1988. 317-33.

Andrade,António Banha de. “Constantes históricas do espaço português”. Problemas do espaço português (Curso de Extensão Universitária). Lisboa: Junta de Investigaçcões do Ultramar, 1972. 19-70.

Andrade, Theophilo de. "Camões, sebastianista avant la lettre". Boletim da Sociedade de Geografia 90/7-9, 10-12 (1972): 135-38. 
Barthes, Roland. The Rustle of Language. Richard Howard, trad. Berkeley: U of California P, 1989.

Boletim Geral das Colónias 15 (173) (Novembro de 1939) (Dedicado à viagem de sua Excelência o Senhor Presidente da República à Àfrica acompanhado de sua Excelência o Senhor Ministro das Colónias).

Boletim Geral das Colónias 20 (234) (Dezembro de 1944) (Dedicado à viagem do Eminentíssimo Legado «a latere» do Soberano Pontífice, Cardeal Dom Manuel Gonçalves Cerejeira, Patriarca de Lisboa, a Cabo Verde, S. Tomé e Príncipe, Angola e Moçambique).

Camões, Luís de. Os Lusíadas. Henrique Barrilaro Ruas, ed. Lisboa: Editora Rei dos Livros, 2002.

Ciacchi, Andrea. “A irresistível ascensão de Antônio Balduíno”. Quaderni IberoAmericani: Attualità Culturale della Penisola Iberica e America Latina 74 (Dec. 1993): 95-104.

Derrida, Jacques. L'autre cap. París: Les Éditions de Minuit, 1991.

Dussel, Enrique. 1492: El encubrimiento del otro. Hacia el origen del "mito de la modernidad”. Bogotá: Ediciones Antropos, Ltda., 1992.

Hacia una filosofía política crítica. Bilbao: Editorial Desclée de Brouwer, 2001.

Eco, Umberto. La isla del día de antes. Barcelona: Lumen, 1995.

Ferro, António. Salazar: o homem e a sua obra. Lisboa: Edições Fernando Pereira, 1982.

Halperín, Jorge. Conversaciones con Saramago: Reflexiones desde Lanzarote. Barcelona: Icaria, 2002.

Jameson, Fredric. A Singular Modernity: Essay on the Ontology of the Present. Londres/ Nueva York: Verso, 2002.

Lourenço, Eduardo. O Labirinto da saudade. Lisboa: Dom Quixote, 1978. Mitologia da saudade, seguido de Portugal como destino. São Paulo: Companhia de Letras, 1999. “Pessoa y Saramago”. Ínsula 663 (Marzo 2002): 4-5.

Macherey, Pierre. Pour une théorie de la production littéraire. París: François Maspéro, 1966.

Medina, João. Salazar, Hitler e Franco: estudos sobre Salazar e a Ditadura. Lisboa: Livros Horizonte, 2000.

Mello, Martinho Nobre de. “Embaixador de Portugal, Carta de 6 de Março de 1936”. Arquivo Oliveira Salazar/ Correspondência Oficial/Negócios Estrangeiros. 4D, Pasta 4.

Mignolo, Walter D. "La colonialidad global, capitalismo y hegemonía epistémica”. Culturas imperiales: experiencia y representación en América, Asia y África. Ricardo Salvatore, ed. Rosario: Beatriz Viterbo Editora, 2005. 55-88. 
Neruda, Pablo. Confieso que he vivido. Hernán Loyola, ed. Barcelona: Random House, 2003.

Las uvas y el viento. Hernán Loyola, ed. Barcelona: Random House, 2005.

Pessoa, Fernando. Crítica: Ensaios, artigos e entrevistas. Fernando Cabral Martins, ed. Lisboa: Assírio \& Alvim, 1999. Mensagem. Lisboa: Edições Ática, 1979. Páginas de pensamento político (1910-1919). Vol. 1. António Quadros, ed. Lisboa: Publicações Europa-América, 1986. Páginas de pensamento político (1925-1935). Vol. 2. António Quadros, ed. Lisboa: Publicações Europa-América, 1986.

Páginas sobre literatura eestética. António Quadros, ed. Lisboa: Publicações Europa-América, 1986. Poesias. Lisboa: Edições Ática, 1980. Poesias de Álvaro Campos. Lisboa: Edições Ática, 1980. Ultimatum e páginas de sociologia política. Maria Isabel Rocheta, Maria Paula Mourão y Joel Serrão, eds. Lisboa: Ática, 1980.

Pires, José Cardoso. Balada da praia dos cães: Dissertação sobre um crime. Lisboa: Dom Quixote, 1999.

Reis, Carlos. Diálogos com José Saramago. Lisboa: Caminho, 1998.

Rosa, João Guimarães. Sagarana. Rio de Janeiro: Editora Nova Fronteira, 1984.

Said, Edward. Beginnings: Intention and Method. Nueva York: Basic Books, 1975.

Salazar, António de Oliveira. Discursos e notas políticas (1935-1937). Vol. 2. Coimbra: Coimbra Editora, 1937.

Santos, Maria Irene Ramalho de Sousa. Atlantic Poets: Fernando Pessoa's Turn in Anglo-American Modernism. Hanover: UP of New England, 2003.

Saramago, José. O ano da morte de Ricardo Reis. Lisboa: Editorial Caminho, 1985.

El año de la muerte de Ricardo Reis. Basilio Losada, trad. La Habana: Editorial Arte y Literatura, 2001. História do cerco de Lisboa. Lisboa: Caminho, 1987. Jangada de pedra. Lisboa: Caminho, 1986. Levantado do chão. Lisboa: Caminho, 1980. "Nobel Lecture. De como a personagem foi mestre e o autor seu aprendiz". Nobelprize.org. 1998. 25 mayo 2007 <http://nobelprize.org/nobel_prizes/ literature/laureates/1998/saramago-lecture.html>

Soares, Bernardo. Livro do desassossego. Richard Zenith, ed. Lisboa: Assírio \& Alvim, 1998. 
Trigueiros, Luís Forjaz. "Visão socio-política da futura Europa nos séculos XV e XVI”. Boletim da Sociedade de Geografia de Lisboa 90/7-9, 10-12 (1972): 177-84.

Unamuno, Miguel de. "Portugal”. Obras Completas. Ricardo Senable, ed. Vol 7. Madrid: Fundación José Antonio de Castro, 2004. 209-222. Biblioteca Virtual Miguel de Cervantes. Alicante, 2006. 20 mayo $2007<\mathrm{http} / / / \mathrm{www}$. cervantesvirtual.com/FichaObra.html?Ref=16684>

Valéry, Paul. Oeuvres. Jean Hytier, ed. París: Éditions Gallimard, 1960.

Vallejo, César. Escritos en prosa. Claudio Caisso, ed. Buenos Aires: Editorial Losada, 1994.

Vásquez Medel, Manuel Ángel. "Pessoa revisitado: El año de la muerte de Ricardo Reis, de José Saramago”. Ínsula 663 (2002): 5-7.

Williams, Raymond. The Politics of Modernism: Against the New Conformists. Tony Pinkney, ed. Londres: Verso, 1989. 